\title{
Mechanical Thrombectomy with Stent Retrievers in Acute Basilar Artery Occlusion
}

\author{
M. Möhlenbruch, S. Stampfl, L. Behrens, C. Herweh, S. Rohde, M. Bendszus, C. Hametner, S. Nagel, P.A. Ringleb, and M. Pham
}

\begin{abstract}
BACKGROUND AND PURPOSE: Basilar artery occlusion remains one of the most devastating subtypes of ischemic stroke. The prognosis is poor if early recanalization is not achieved. The purpose of this study was to evaluate the safety and technical feasibility of selfexpanding retrievable stents in the endovascular treatment of acute basilar artery occlusion.
\end{abstract}

MATERIALS AND METHODS: Twenty-four patients with acute basilar artery occlusion were treated with Solitaire FR or Revive SE devices between December 2009 and May 2012. Additional treatment included intravenous and/or intra-arterial thrombolysis (21/24) and percutaneous transluminal angioplasty/permanent stent placement (7/24). Recanalization was assessed by means of the $\mathrm{TICl}$ score. Clinical outcome was determined at discharge (NIHSS), and at 3 months (mRS).

RESULTS: Median NIHSS score on admission was 24 ; median duration of symptoms was 254 minutes. Successful recanalization (TICI $2 b+3$ ) by thrombectomy only was achieved in 18 patients (75\%). Intracranial stent deployment after thrombectomy caused by underlying atherosclerotic stenosis was performed in 7 patients. If these patients with intracranial stent placement are included, successful recanalization was achieved in 21 of 24 patients (87.5\%). NIHSS improvement $\geq 10$ points was reached in $54 \%$ of patients $(n=13 / 24)$. Mortality during the first 3 months was $29 \%$ (7/24). After 3 months, 8 patients (33\%) had a favorable clinical outcome (mRS 0-2).

CONCLUSIONS: In our series, application of self-expanding retrievable stents in acute basilar artery occlusion resulted in a high recanalization rate without procedural complications and good clinical outcome in one-third of patients.

ABBREVIATIONS: BAO = basilar artery occlusion; IAT = intra-arterial thrombolysis; $\mathrm{MT}=$ mechanical thrombectomy

B asilar artery occlusion (BAO), representing $20 \%$ of all ischemic strokes occurring in the posterior circulation, remains the stroke subtype with the highest mortality rate by far. ${ }^{1}$ Severe neurologic and non-neurologic sequelae are caused by ischemic infarction of brain stem parenchyma, cranial nerve nuclei, and autonomic centers, with death and dependency rates exceeding $70 \%$ even after treatment. ${ }^{2}$

Regardless of treatment, recanalization of an occluded basilar artery is the single greatest predictor of good outcome. ${ }^{3}$ The likelihood of a good outcome in nonrecanalized patients is approximately $13 \%{ }^{4}$ There exists only limited data on the efficacy of different recanalization strategies to achieve complete recanalization of the occluded vessel segment. ${ }^{1}$ Either intravenous or local

Received June 10, 2013; accepted after revision September 13

From the Departments of Neuroradiology (M.M., S.S., L.B., C.H., S.R., M.B., M.P.) and Neurology (C.H., S.N., P.A.R.), University of Heidelberg Medical Center, Heidelberg, Germany.

Please address correspondence to Markus Möhlenbruch, MD, Department of Neuroradiology, University of Heidelberg Medical Center, Im Neuenheimer Feld 400, 69120 Heidelberg, Germany; e-mail: markus.moehlenbruch@med.uni-heidelberg.de http://dx.doi.org/10.3174/ajnr.A3796 intra-arterial administration of thrombolytics has shown low rates of recanalization in approximately $60 \%$ of cases and consequently has been associated with poor clinical outcome. Given the poor results in achieving complete vessel recanalization by pharmacologic intravenous or local intra-arterial thrombolysis (IAT), more effective recanalization strategies are highly desirable, and many centers favor additional mechanical thrombectomy (MT). A variety of intra-arterial devices intended to disrupt, stent, or aspirate the thrombus has been reported for recanalization of basilar artery occlusions. ${ }^{5-10}$ Recently, the appearance of self-expanding retrievable stents (stent retriever), which have increased recanalization rates to $>90 \%$ in the anterior circulation, ${ }^{11-14}$ has brought up a promising alternative to all other therapeutic strategies. While an increasing number of studies has investigated the use of stent retrievers in anterior circulation, employment in acute BAO has been reported infrequently and in most studies with $<20$ patients (Table 1 ).

We investigated a series of 24 patients with acute BAO thus far treated by stent retrievers and analyzed safety and efficacy data as well as clinical results.

AJNR Am J Neuroradiol 35:959-64 May 2014 www.ajnr.org 
Table 1: Comparison of baseline stroke severity and outcome variables between this study and others with the use of a stent retriever in acute basilar artery occlusion

\begin{tabular}{|c|c|c|c|c|c|c|}
\hline & $\begin{array}{l}\mathrm{N}(\mathrm{BAO}) / \mathrm{N} \\
\text { (Total) }\end{array}$ & NIHSS Initial & $\begin{array}{l}\text { Successful Recanalization } \\
\text { (TICI 2b-3), \% }\end{array}$ & sICH, \% & $\begin{array}{l}\text { mRS 0-2 After } \\
90 \text { Days, \% }\end{array}$ & $\begin{array}{c}\text { 90-Day } \\
\text { Mortality, \% }\end{array}$ \\
\hline Roth et $\mathrm{al}^{23}$ & $8 / 22$ & 19 & 87.5 & 12.5 & 37.5 & 50 \\
\hline Miteff et $\mathrm{al}^{24}$ & $10 / 26$ & 31 & 100 (TIMI 3 in 33) $^{a}$ & 10 & 20 & 33 \\
\hline Costalat et al ${ }^{25}$ & $16 / 50$ & $?$ & $81(\mathrm{TICl} 3)$ & 6.3 & 44 & 25 \\
\hline Dorn et $\mathrm{al}^{26}$ & $24 / 108$ & 16 & 77.9 & NA & NA & $47.8^{\mathrm{b}}$ \\
\hline Mordasini et $\mathrm{al}^{27}$ & $14 / 14$ & 21 & 100 & 0 & 29 & 36 \\
\hline Espinosa et $\mathrm{al}^{28}$ & $18 / 18$ & 20 & 94 & 0 & 50 & 22 \\
\hline Mourand et $\mathrm{al}^{29}$ & $31 / 31$ & 38 & 74 & 16 & 35 & 32 \\
\hline Study group & $24 / 24$ & 24 & 87.5 & 8 & 33 & 29 \\
\hline
\end{tabular}

Note:- N indicates number of patients; NA, not available; sICH, symptomatic intracerebral hemorrhage.

a TIMI (Thrombolysis In Myocardial Infarction) grade 2 or 3; b at discharge.

\section{MATERIALS AND METHODS}

Approval for prospective data collection of all interventional procedures reported in this study was given by the institutional review board. Patient informed consent for study inclusion was obtained from the patients or their legal representatives.

On the basis of the prospectively collected thrombolysis in stroke data base in Heidelberg since 1998, we analyzed angiographic and clinical data of patients with acute ischemic stroke caused by BAO undergoing endovascular stroke treatment with stent retrievers between December 2009 and May 2012. In our institution, the Solitaire FR Revascularization Device (Solitaire FR; Covidien, Dublin, Ireland) became available in March 2009 and the Revive SE thrombectomy device (Revive SE; Codman \& Shurtleff, Raynham, Massachusetts) in October 2010 for endovascular stroke treatment.

On admission, a stroke neurologist performed physical neurologic examinations and detailed assessment of the NIHSS score. Cranial CT including CT angiography or multimodal stroke MR imaging including dynamic susceptibility contrast perfusion, DWI, and time-of-flight MR angiography was performed in all patients immediately after physical evaluation. Thereafter, intravenous thrombolysis with $\mathrm{rtPA}(0.9 \mathrm{mg} / \mathrm{kg}$ body weight for 40 minutes) was administered as bridging therapy in patients with no contraindications to rtPA. Patients who received intravenous thrombolysis in a tertiary institution and were referred to us for further endovascular therapy were also included in this study.

After the interventional procedure, patients were observed for at least 24 hours in a neurologic intensive care unit, and follow-up CT or MR imaging was routinely performed at 20-36 hours after treatment, or earlier if neurologic deterioration occurred. Postinterventional NIHSS and mRS were assessed by detailed physical examinations performed by an independent stroke neurologist at discharge. MR spectroscopy at 3 months was obtained during a standardized telephone follow-up or an outpatient visit. As a common definition of good outcome, an mRS score of 0-2 was adopted and for poor functional outcome a score of 3-6 was adopted. ${ }^{15}$ Stroke etiology was classified according to TOAST criteria. $^{16}$

\section{Procedure}

All interventions were performed by board-certified consultant neurointerventionalists on a biplanar system (Artis zee Biplane; Siemens, Erlangen, Germany) under general anesthesia. Using transfemoral access, a $6 \mathrm{~F}$ guiding catheter (Envoy; Codman \&
Shurtleff or Neuron; Penumbra, Alameda, California) was placed into the dominant or most accessible vertebral artery. During the study period, mechanical thrombectomy was performed with the use of Solitaire FR or Revive SE. A microcatheter (Prowler Select Plus, Codman \& Shurtleff; or Rebar 27, Covidien) with a 0.014-inch microwire (Transcend; Stryker, Kalamazoo, Michigan) was carefully advanced through the thromboembolic occlusion under fluoroscopic control. Angiographic runs were subsequently performed through the microcatheter to document the correct position of the microcatheter tip at least $0.5 \mathrm{~cm}$ beyond the distal end of the thrombus. Under fluoroscopic control, the stent retriever was advanced through the microcatheter across the vessel occlusion with the distal stent markers beyond the distal end of the occlusion. The stent was deployed/unsheathed completely by pulling back the microcatheter over the proximal marker, and angiographic runs were performed to control for flow restoration. The duration of stent deployment before its retrieval/thrombectomy maneuver varied between 1-5 minutes if thrombectomy/ mechanical recanalization was the only aim (21/24 patients). If additional intra-arterial local administration of rtPA was performed, longer deployment times of up to 20 minutes were reached (3/24 patients). To perform the mechanical recanalization/thrombectomy maneuver, the microcatheter was withdrawn with the deployed/unsheathed stent retriever at fixed distance from the microcatheter tip under simultaneous aspiration with a 20 - $\mathrm{mL}$ syringe at the guide catheter. In the case of persistent occlusion or incomplete vessel recanalization, the device was cleaned and reinserted for repeated thrombectomy.

As a supplement to thrombectomy, we used intra-arterial rtPA if distal branch occlusions persisted. If there was an underlying stenosis or insufficient recanalization, we eventually performed additional balloon angioplasty and permanent endovascular stent placement (Solitaire FR or Enterprise; Codman \& Shurtleff). The maximum dose of intra-arterial rtPA was $21 \mathrm{mg}$. Other periprocedural medications in selected patients $(12 / 24)$ included an IV bolus of $500 \mathrm{mg}$ of aspirin or $5000 \mathrm{U}$ of heparin or tirofiban (administered intravenously, at an initial rate of $0.4 \mu \mathrm{g} / \mathrm{kg}$ per minute for 30 minutes and continued at $0.1 \mu \mathrm{g} / \mathrm{kg}$ per minute for 24 or 48 hours). If permanent stent deployment was performed, postprocedural medication with $100 \mathrm{mg}$ of aspirin and $300 \mathrm{mg}$ of clopidogrel (subsequently $75 \mathrm{mg}$ for 3 months) was initiated.

The extent of recanalization was classified according to the TICI grading scale. ${ }^{17}$ TICI grades $2 \mathrm{~b}$ and 3 were rated as sufficient 
recanalization, whereas TICI grades $0-2$ a were rated as insufficient recanalization. Assessment of angiographic images was performed in consensus by 2 board-certified interventional neuroradiologists (M.M., S.S.) with more than 5 years of training.

The following time points were recorded for analysis: onset of symptoms, first angiogram, and achievement of final recanalization result. Time intervals from symptom onset to the first angiogram and procedure time to final recanalization (time to recanalization) were calculated. Furthermore, images were evaluated regarding level and length of the occlusion (in millimeters, by use of CTA or MRA), posterior circulation ASPECTS (by use of CT angiography source images or MR imaging DWI), and number of stent deployments necessary for recanalization. ${ }^{18}$ Postprocedural hemorrhage was rated according to PROACT II criteria.

\section{Statistics}

Categoric data in contingency tables were analyzed by use of the Fisher exact test. Nonparametric pair-wise comparisons were performed with the use of the Wilcoxon test (procedure "rank sum" for unmatched data). Statistical analyses were performed by use of PASW Statistics, Version 18.0 (IBM, Armonk, New York). Statistical significance was assumed at an $\alpha$ level of $P<.05$ (2-sided). To test the effects of age, admission NIHSS score, time from symptom onset, and recanalization status on outcome, univariate logistic regression analyses were calculated ("logistic" procedure of STATA 12; StataCorp, College Station, Texas).

\section{RESULTS}

Between December 2009 and May 2012, endovascular therapy was performed on 31 patients for BAO. Of these, 7 patients were excluded because of endovascular treatment technique with either exclusive local intra-arterial thrombolysis or primary stent placement for high-grade basilar artery or distal vertebral artery stenosis. Twenty-four patients ( 17 male, 7 female; median age, 70; range, 33-83 years) underwent $\mathrm{MT}$. In this group, $63.3 \%$ had hypertension, $50.0 \%$ had hypercholesterolemia, $33.3 \%$ had atrial fibrillation, $33.3 \%$ had a history of previous TIA or stroke, $23.3 \%$ had diabetes, $23.3 \%$ were current smokers, and $20 \%$ had coronary artery disease. Stroke etiology was categorized in accordance with TOAST classification: large-vessel disease in 7 (29.2\%) patients, cardioembolic cause in $11(45.8 \%)$ patients, both (large-vessel disease and cardioembolic) in $4(16.7 \%)$ patients, and undetermined in $2(8.3 \%)$ patients.

The site of BAO was partial basilar tip $(1 / 24 ; 4.2 \%)$, distal to anterior ICA offspring to basilar tip (13/24; 54.2\%), midbasilar without basilar tip $(6 / 24 ; 25 \%)$, proximal basilar artery with 1 vertebral artery $(2 / 24 ; 8.3 \%)$, and proximal basilar artery with both vertebral arteries $(2 / 24 ; 8.3 \%)$. The median length of the occluded basilar artery segment was $17 \mathrm{~mm}$ (minimum, $5 \mathrm{~mm}$; maximum, $50 \mathrm{~mm}$ ).

Twenty-one patients $(87.5 \%)$ received intravenous $\mathrm{rtPA}$ as bridging therapy before endovascular therapy, with a median dose of $50 \mathrm{mg}$ (minimum, $36 \mathrm{mg}$; maximum, $90 \mathrm{mg}$ ), and local intra-arterial thrombolysis as an adjunctive therapy was given in 6 patients (25\%), with median dose of $18 \mathrm{mg}$ (minimum, $13 \mathrm{mg}$; maximum, $21 \mathrm{mg}$ ).

The median time interval from symptom onset to first angio- gram was 254 minutes (range, 125-827 minutes), and median procedure time from first angiogram to recanalization was 77 minutes (range, 30-324 minutes).

Nine patients were treated with Solitaire FR, 12 patients with Revive SE, 2 patients with both devices, and in 1 patient delivery of the stent retriever was technically not feasible due to tortuous anatomy of aortic arch or right vertebral artery. The median number of passes for Solitaire FR or Revive SE was 2 (range, 1-10).

Initial TICI score before recanalization was 0 in 22 patients and 1 in 2 patients. After MT, successful recanalization defined as TICI score $2 \mathrm{~b}$ or 3 was achieved in 18 patients (75\%; TICI $2 \mathrm{~b}$ in $n=9$; TICI 3 in $n=9$ ). Two of 24 patients were recanalized partially according to TICI 2 a. Additional intracranial stent deployment after MT due to an underlying atherosclerotic stenosis was performed in 7 patients. In 3 of these patients, the TICI score subsequently improved from $0-2 \mathrm{~b}(n=1)$, from $1-2 \mathrm{~b}(n=1)$, and from $2 \mathrm{a}-2 \mathrm{~b}(n=1)$. In the remaining 4 patients, the TICI score did not differ from previous MT [TICI $2 \mathrm{a}(n=1) ; 2 \mathrm{~b}(n=$ $1) ; 3(n=2)$ ]. Overall, after MT alone or in combination with intracranial stent placement, successful recanalization was achieved in 21 of 24 patients ( $87.5 \%$; TICI $2 \mathrm{~b}$ in $n=12$; TICI 3 in $n=9$ ). Extracranial stent placement was performed in 2 patients (in 1 patient with a severe $90 \%$ atherosclerotic stenosis in V1 and in another patient with dissection in V2 caused by the guiding catheter). Table 2 gives an overview of the patient angiographic and treatment data.

Asymptomatic postprocedure hemorrhage (HI1) occurred in 1 patient, and symptomatic intracranial hemorrhage ( $\mathrm{PH} 2)$ with lethal consequence appeared in another patient.

After stent retrieval, thromboembolic occlusion of a previously unaffected artery was observed in 4 of 24 (16\%) patients (P2/P3 segment, $n=1$; PICA, $n=2$; superior cerebellar artery, $n=1)$. Severe vasospasm was detected in 2 patients, which resolved after intra-arterial administration of nimodipin.

Among all patients, median NIHSS score on admission was 24 (range, 7-42) and at discharge, 5 (range, 0-28), keeping in mind the impreciseness of this score in vertebrobasilar strokes and the arbitrary values in intubated patients. NIHSS improvement $\geq 10$ points was reached in $54 \%$ of patients $(n=13 / 24)$. Mortality at discharge was $25 \%(n=6)$ and at 3 months $29 \%(n=7)$, respectively. After 3 months, 8 patients $(33 \%)$ had a favorable clinical outcome (mRS $0-2), 4$ patients (17\%) were mRS 3, two patients $(8 \%)$ were mRS 4 , and $3(13 \%)$ patients were mRS 5 . Table 3 shows the outcome and complications of the treated patients. The strongest predictor of favorable outcome, with an odds ratio of $3.51(P=.10$; CI: $0.65-18.9)$, was recanalization status after thrombectomy as graded by the TICI scale. With an odds ratio of 0.58 , the NIHSS score on admission also was a strong predictor of outcome with a trend toward statistical significance in this small sample ( $P=.081$, CI: $0.31-1.06)$. Older patients tended to have worse outcome with an odds ratio of 0.93 (CI: 0.85-1.00; $P=$ .067). Interestingly, time from symptom onset to endovascular treatment (range, 2 hours, 5 minutes to 13 hours, 47 minutes) did not exert a strong influence on outcome (odds ratio $=0.99 ; P=$ .21; CI: 0.98-1.00).

After dichotomization, by use of the posterior circulation ASPECTS score at a cutoff value of $\geq 9$, NIHSS score at discharge 


\begin{tabular}{|c|c|c|c|c|c|c|c|c|}
\hline Patient No. & $\mathrm{TICl}$ at Baseline & $\mathrm{TICl}$ at End Point & No. of Passes & Type of Device & $\begin{array}{l}\text { Intracranial Stent } \\
\text { Placement }\end{array}$ & IV rtPA & IA rtPA & $\begin{array}{l}\text { Concurrent } \\
\text { Medication }\end{array}$ \\
\hline 1 & 0 & 3 & 1 & $\mathrm{~S}$ & 0 & 54 & 20 & 0 \\
\hline 2 & 0 & 3 & 4 & S & 0 & 0 & 0 & A \\
\hline 3 & 0 & $2 b$ & 4 & $S$ & 0 & 55 & 20 & $\mathrm{~T}$ \\
\hline 4 & 0 & $2 b$ & 2 & S & 1 & 35 & 21 & $\mathrm{~T}$ \\
\hline 5 & 0 & $2 b$ & 2 & S & 1 & 41 & 13 & $\mathrm{~T}$ \\
\hline 6 & 0 & $2 a$ & 1 & S & 1 & 47 & 16 & $\mathrm{~T}$ \\
\hline 7 & 0 & 3 & 2 & S & 1 & 52 & 0 & $\mathrm{~T}$ \\
\hline 8 & 0 & $2 b$ & 1 & $\mathrm{R}$ & 0 & 50 & 16 & $T$ \\
\hline 9 & 0 & 3 & 4 & $\mathrm{R}$ & 0 & 45 & 0 & 0 \\
\hline 10 & 0 & 0 & 0 & 0 & 0 & 50 & 0 & 0 \\
\hline 11 & 0 & $2 b$ & 7 & $\mathrm{R}$ & 1 & 0 & 0 & $T$ \\
\hline 12 & 0 & $2 b$ & 3 & $R$ & 1 & 67 & 0 & $\mathrm{~T}$ \\
\hline 13 & 0 & $2 b$ & 2 & $R$ & 0 & 50 & 0 & 0 \\
\hline 14 & 0 & 3 & 1 & $R$ & 0 & 90 & 0 & 0 \\
\hline 15 & 0 & $2 b$ & 1 & $R$ & 0 & 43 & 0 & $\mathrm{H}$ \\
\hline 16 & 0 & 3 & 2 & $R$ & 0 & 69 & 0 & 0 \\
\hline 17 & 0 & $2 b$ & 2 & $R$ & 0 & 90 & 0 & 0 \\
\hline 18 & 0 & 3 & 6 & $\mathrm{R}, \mathrm{S}$ & 0 & 0 & 0 & 0 \\
\hline 19 & 1 & $2 b$ & 2 & $S$ & 0 & 50 & 0 & 0 \\
\hline 20 & 0 & $2 b$ & 3 & $R$ & 0 & 38 & 0 & 0 \\
\hline 21 & 0 & 3 & 1 & $S$ & 1 & 73 & 0 & $\mathrm{~T}$ \\
\hline 22 & 0 & 3 & 2 & $R$ & 0 & 60 & 0 & 0 \\
\hline 23 & 0 & 0 & 10 & $\mathrm{R}, \mathrm{S}$ & 0 & 68 & 0 & $T$ \\
\hline 24 & 1 & $2 b$ & 4 & $\mathrm{R}$ & 0 & 60 & 0 & 0 \\
\hline
\end{tabular}

Note:- "No. of Passes" refers to the number of passes needed for recanalization. A indicates aspirin; H, heparin; R, Revive SE; S, Solitaire FR; T, tirofiban; IA, intra-arterial.

Table 3: Patient outcomes/complications

\begin{tabular}{|c|c|c|c|c|c|c|}
\hline $\begin{array}{l}\text { Patient } \\
\text { No. }\end{array}$ & $\begin{array}{l}\text { NHISS at } \\
\text { Baseline }\end{array}$ & $\begin{array}{l}\text { NHISS at } \\
\text { Discharge }\end{array}$ & $\begin{array}{c}\text { mRS at } \\
\text { Discharge }\end{array}$ & $\begin{array}{l}\text { mRS at } \\
90 \text { Days }\end{array}$ & $\mathrm{ICH}$ & Complication \\
\hline 1 & 17 & 0 & 1 & 0 & 0 & 0 \\
\hline 2 & 38 & 7 & 5 & 5 & 0 & 0 \\
\hline 3 & 35 & a & 6 & 6 & AS & 0 \\
\hline 4 & 19 & 1 & 2 & 5 & 0 & OUA \\
\hline 5 & 26 & a & 6 & 6 & 0 & OUA \\
\hline 6 & 38 & 17 & 4 & 4 & 0 & 0 \\
\hline 7 & 16 & 2 & 2 & 3 & 0 & 0 \\
\hline 8 & 39 & a & 6 & 6 & $\mathrm{~S}$ & 0 \\
\hline 9 & 42 & 22 & 5 & 6 & 0 & 0 \\
\hline 10 & 40 & a & 6 & 6 & 0 & 0 \\
\hline 11 & 21 & 28 & 5 & 5 & 0 & VAS \\
\hline 12 & 7 & a & 6 & 6 & 0 & OUA \\
\hline 13 & 22 & 2 & 3 & 2 & 0 & D V2 \\
\hline 14 & 30 & 5 & 3 & 3 & 0 & 0 \\
\hline 15 & 27 & 1 & 1 & 2 & 0 & D V1 \\
\hline 16 & 22 & 4 & 3 & 2 & 0 & 0 \\
\hline 17 & 10 & 6 & 4 & 2 & 0 & OUA \\
\hline 18 & 37 & 8 & 4 & 3 & 0 & D V1 \\
\hline 19 & 12 & 3 & 3 & 2 & 0 & D V2 \\
\hline 20 & 21 & 15 & 5 & 4 & 0 & 0 \\
\hline 21 & 30 & 4 & 3 & 2 & 0 & 0 \\
\hline 22 & 24 & 0 & 0 & 0 & 0 & VAS \\
\hline 23 & - & a & 6 & 6 & 0 & 0 \\
\hline 24 & 17 & 10 & 4 & 3 & 0 & 0 \\
\hline
\end{tabular}

Note:-AS indicates asymptomatic; D, dissection; OUA, thromboembolic occlusion of a previously unaffected artery; S, symptomatic; V1, V2, segment of the vertebral artery; VAS, vasospasm; -, absent.

a Deceased.

$(P=.03), \mathrm{mRS}$ at discharge $(P=.004)$, and mRS at 3 months $(P=.02)$ were significantly better in patients with ASPECTS $\geq 9$. Mortality in patients with ASPECTS $\geq 9$ was significantly lower: $9 \%$ versus $29 \%, P=.034$.

\section{DISCUSSION}

The first description of the use of IAT in BAO was published in the early 1980s. ${ }^{19}$ Since that time, multiple series describing the use of
IAT in BAO have been published. A large meta-analysis that incorporated 10 studies including 316 patients reported an overall recanalization rate of $64 \%$ and overall mortality of $56 \%$. The mortality was $87 \%$ in nonrecanalized patients and $37 \%$ in recanalized patients $(P<.001) .{ }^{20}$ In the most recent and largest series to date, the data of 180 adult patients with angiographically confirmed basilar occlusion treated with IAT at 5 German stroke centers were retrospectively evaluated. Patients with partial or complete recanalization had a significantly better neurologic outcome than nonrecanalized patients $(P<.001)$, highlighting that complete or at least partial recanalization of the occlusion is essential for a favorable neurologic outcome. However, the overall recanalization rates of approximately $55 \%$ for IAT have remained low in these published series. ${ }^{21}$ As a second major disadvantage of IAT, the time to recanalization is prolonged because it takes time to dissolve the thrombus after initial catheterization. ${ }^{12}$ In accordance with these limitations, a previous meta-analysis showed that the overall proportion of patients achieving a favorable outcome after IAT remains low (good or favorable outcome in $24 \%)^{22}$

Therefore, various investigators have assessed the use of MT in small BAO case series ( $<16$ patients with exception of the MERCI and Multi-MERCI trails) with different devices including simple clot disruption, ${ }^{5}$ manual aspiration, ${ }^{6}$ AngioJet catheter (Possis Medical, Minneapolis, Minnesota), ${ }^{7}$ Amplatz Goose Neck Snare (Microvena, White Bear Lake, Minnesota), ${ }^{8}$ Merci retriever (Concentric Medical, Mountain View, California), ${ }^{9}$ and the Penumbra aspiration catheter. ${ }^{10}$ In these studies, the successful recanalization rate varied between $50-100 \%$ and good clinical outcome ranged between $25-50 \%$.

With the introduction of stent retrievers, which combine the advantages of temporary stent placement with immediate flow 
restoration and thrombectomy with definite thrombus removal, increased recanalization rates of up to $100 \%$ have been reported. ${ }^{11-14}$ However, only limited data about treatment of acute BAO with stent retrievers are presented in the literature (Table 1). ${ }^{23-29}$

Costalat et $\mathrm{al}^{25}$ included 16 acute BAOs in their series of 50 patients with intracranial vessel occlusion and treated with the Solitaire FR. Successful recanalization (defined as TICI 3) was obtained in $81 \%(13 / 16)$, with a mean of 2.1 passes. One patient had a symptomatic intracranial hemorrhage. Good functional outcome (mRS of $0-2$ ) at 3 months was achieved in $44 \%(7 / 16)$, and mortality rate was $25 \%(4 / 16) .{ }^{25}$ Mordasini et al ${ }^{27}$ presented a series with 14 acute BAOs treated with Solitaire FR. Successful recanalization (defined as TICI 2 b or 3 ) was reached in all cases, with a mean of 1.3 passes. There was no symptomatic intracranial hemorrhage. At 3 months, good functional outcome (mRS 0-2) was observed in $28.6 \%$ (4/14) and overall mortality was $35.7 \%$ $(5 / 14) .{ }^{27}$ Espinosa de Rueda et al $^{28}$ treated 18 patients with Solitaire AB/FR or Trevo Pro (Stryker) with a mean of 1.7 passes. Successful recanalization (defined as TICI 2b or 3) was obtained in $94.4 \%(17 / 18)$ with good functional outcome (mRS $0-2)$ in $50 \%(9 / 17)$. No symptomatic intracranial hemorrhage was found, and mortality rate was $22.2 \%(5 / 17){ }^{28}$

In our series, we used 2 different stent retrievers. The first 9 patients were treated with the Solitaire FR and in the following 14 patients the Revive SE was used with changeover to the Solitaire FR in 2 cases. For both stent retrievers, the median number of passes was 2. In 1 of the 2 patients in which both devices (Solitaire FR after Revive SE) were used, successful recanalization was achieved only after the use of a slightly oversized Solitaire FR (6 $\mathrm{mm}$ in diameter) because the diameter of the basilar artery was very large, measuring nearly $5 \mathrm{~mm}$. In the other patient, the basilar artery remained occluded despite 5 attempts with Revive SE, another 5 attempts with Solitaire FR, and even after eventual percutaneous transluminal angioplasty.

Thromboembolic events in previously unaffected proximal or distal portions of the posterior cerebral artery territories occurred in 2 patients distally ( $8 \%$ ) and in 2 patients proximally $(8 \%)$. Distal occlusion of previously patent branches is most likely to be explained by fragmentation and embolization of the clot during retrieval into the guiding catheter. This rate of embolism in our series is higher than what is reported for the anterior circulation. ${ }^{30}$ One possible reason might be the different vessel anatomy in the posterior circulation, which is more tight and curved with possibly more tapering and deformation of the device while being withdrawn. To overcome this problem, we constantly attempted to advance the $6 \mathrm{~F}$ guiding catheter as high/distal as possible so as to approach the deployed stent retriever as close as possible to optimize complete and effective aspiration of all thrombus material during retrieval. A potential drawback with this approach is possible vessel dissection occurring in 4 patients, emphasizing the application of a more flexible distal access catheter instead of stiffer guiding catheters.

In our series with 24 patients, successful recanalization was achieved in $75 \%$, which is lower than the reported rate in the anterior circulation. Together with additional intracranial stent placement, we found that our successful recanalization of $87.5 \%$ is in line with the previous data (Table 1). These numbers reflect the higher incidence of a high-grade stenosis in the posterior circulation with consecutive atherothrombotic occlusions, caused by local thrombosis on the surface of ulcerated atherosclerotic plaques. The reported incidence in the literature of $35 \%$ of atherothrombotic lesions in patients with acute $\mathrm{BAO}$ is similar to our rate of $29 \% .^{3}$

After pretreatment intravenous thrombolysis with rtPA, no shift in occlusion site or recanalization rate was observed on preinterventional DSA compared with initial CTA or MRA. Whether pretreatment intravenous thrombolysis helped with recanalization cannot be proved in the face of the low recanalization failure rate.

However, despite the high successful recanalization rate, favorable clinical outcome was limited. The proportion of patients who gained independence (mRS $0-2$ ) after 3 months was $33 \%$ $(n=8 / 24)$. Two patients discharged with mRS 2, 1 week after onset, had subsequent MCA infarction during the follow-up period with the result of mRS 3 and mRS 5, respectively. Applying the definition of good neurologic outcome according to the SWIFT study, $54 \%$ of patients $(n=13 / 24)$ met the criteria for a good neurologic outcome. ${ }^{31}$

Some predictors influence clinical outcome independently from successful recanalization, such as high initial NIHSS/low Glasgow Coma Scale scores, age, thrombus volume, etiology, site of occlusion, time span from onset to recanalization, and brain stem DWI score or the posterior circulation ASPECTS. ${ }^{18}$ In this study, NIHSS score on admission and age could be identified as predictors of outcome, however only with a trend toward statistical significance. This reflects one major limitation of our study, which is restriction to a single center and small sample size. Interestingly, time from onset to endovascular treatment did not exert a strong influence on outcome. This finding is in accordance with the observation that extended treatment windows of up to 12 hours in posterior circulation ischemic stroke are possible if irreversible extended brain stem infarction is ruled out by pretreatment DWI-MR imaging. ${ }^{32}$ With the use of the posterior circulation ASPECTS in our series, patients with posterior circulation ASPECTS score $\geq 9$ had a significantly better outcome $(50 \%, n=$ $6 / 12$, mRS $0-2$ after 3 months) than patients with posterior circulation ASPECTS score $\leq 8(17 \%, n=2 / 12)$, which reveals that extensive and irreversible brain stem damage obviously will indicate poor prognosis regardless of recanalization success.

In 2 of 24 patients in our series ( $8 \%)$, intracranial hemorrhage (HI1, $n=1$; PH2, $n=1$; according to the PROACT II criteria) occurred with fatal outcome (mRS 6 in both; in 1 patient caused by $\mathrm{PH} 2$ and in the other patient caused by extensive brain stem infarction). Recanalization had been successful in both these patients (TICI 2b) and in both intravenous and intra-arterial lysis with rtPA, and, in addition, a standard dose rate of tirofiban had been given during and after the procedure. These observations in 2 cases of our series indicate that the risk of hemorrhage after recanalization/reperfusion might increase exceptionally with combined administration of intravenous/intra-arterial rtPA and glycoprotein IIb/IIIa antagonists and should therefore not be performed routinely in any interventional treatment of BAO. ${ }^{33} \mathrm{How}-$ ever, the overall rate of intracranial hemorrhage compares favorably with the rates reported in other studies (Table 1). 


\section{CONCLUSIONS}

Treatment of acute BAO with stent retrievers is safe and technically feasible, with high rates of recanalization. However, although feasible and safe, endovascular treatment still must show superiority to intravenous thrombolysis alone. The results encourage further prospective trials to evaluate the potential clinical benefit in patients with acute BAO.

Disclosures: Stefan Rohde_UNRELATED: Payment for Lectures (including service on speakers bureaus): Codman Neurovascular, MicroVention, AB Medica. Martin Bendszus - RELATED: Consulting Fee or Honorarium: Codman, Micrus; Comments: Honoraria for educational talks; UNRELATED: Grants/Grants Pending: Micrus,* Comments: IIS on aneurysm treatment with coils; Payment for Lectures (including service on speakers bureaus): Bayer, Guerbet, Novartis, Codman, Micrus, Comments: Educational talks. Peter Ringleb-UNRELATED: Payment for Lectures (including service on speakers bureaus): Boehringer Ingelheim, Paion, Ferrer, Sanofi, Bayer, GlaxoSmithKline, Comments: Lecture fees for talks about thrombolysis ( ${ }^{*}$ money paid to institution).

\section{REFERENCES}

1. Mattle HP, Arnold M, Lindsberg PJ, et al. Basilar artery occlusion. Lancet Neurol 2011;10:1002-14

2. Ferbert A, Brückmann H, Drummen R. Clinical features of proven basilar artery occlusions. Stroke 1990;21:1135-42

3. Schonewille WJ, Wijman CA, Michel P, et al. Treatment and outcomes of acute basilar artery occlusion in the Basilar Artery International Cooperation Study (BASICS): a prospective registry study. Lancet Neurol 2009:8:724-30

4. Hacke W, Zeumer H, Ferbert A, et al. Intra-arterial thrombolytic therapy improves outcome in patients with acute vertebrobasilar occlusive disease. Stroke 1988;19:1216-22

5. Bergui M, Stura G, Daniele D, et al. Mechanical thrombolysis in ischemic stroke attributable to basilar artery occlusion as first-line treatment. Stroke 2006;37:145-50

6. Chapot R, Houdart E, Rogopoulos A, et al. Thromboaspiration in the basilar artery: report of two cases. AJNR Am J Neuroradiol 2002;23:282-84

7. Mayer TE, Hamann GF, Schulte-Altedorneburg G, et al. Treatment of vertebrobasilar occlusion by a coronary waterjet thrombectomy device: a pilot study. AJNR Am J Neuroradiol 2005;26:1389-94

8. Pfefferkorn T, Mayer TE, Opherk C, et al. Staged escalation therapy in acute basilar artery occlusion: intravenous thrombolysis and ondemand consecutive endovascular mechanical thrombectomy: preliminary experience in $\mathbf{1 6}$ patients. Stroke 2008;39:1496-500

9. Lutsep HL, Rymer MM, Nesbit GM. Vertebrobasilar revascularization rates and outcomes in the MERCI and multi-MERCI trials. $J$ Stroke Cerebrovasc Dis 2008;17:55-57

10. Bose A, Henkes H, Alfke K, et al. The Penumbra system: a mechanical device for the treatment of acute stroke due to thromboembolism. AJNR Am J Neuroradiol 2008;29:1409-13

11. Castaño C, Dorado L, Guerrero C, et al. Mechanical thrombectomy with the Solitaire $\mathrm{AB}$ device in large artery occlusions of the anterior circulation: a pilot study. Stroke 2010;41:1836-40

12. Möhlenbruch M, Seifert M, Okulla T, et al. Mechanical thrombectomy compared to local-intraarterial thrombolysis in carotid $\mathrm{T}$ and middle cerebral artery occlusions: a single center experience. $\mathrm{Clin}$ Neuroradiol 2012;22:141-47

13. Stampfl S, Hartmann M, Ringleb PA, et al. Stent placement for flow restoration in acute ischemic stroke: a single-center experience with the Solitaire stent system. AJNR Am J Neuroradiol 2011;32: 1245-48

14. Rohde S, Haehnel S, Herweh C, et al. Mechanical thrombectomy in acute embolic stroke: preliminary results with the Revive device. Stroke 2011;42:2954-56

15. Van Switen JC, Koudstaal PJ, Visser MC, et al. Interobserver agreement for the assessment of handicap in stroke. Stroke 1988;19: 604-07

16. Adams HP Jr, Bendixen BH, Kappelle LJ, et al. Classification of subtype of acute ischemic stroke: definitions for use in a multicenter clinical trial. TOAST: Trial of Org 10172 in Acute Stroke Treatment. Stroke 1993;24:35-41

17. Higashida RT, Furlan AJ, Roberts $\mathrm{H}$, et al. Trial design and reporting standards for intra-arterial cerebral thrombolysis for acute ischemic stroke. Stroke 2003;34:109-37

18. Puetz V, Sylaja PN, Coutts SB, et al. Extent of hypoattenuation on CT angiography source images predicts functional outcome in patients with basilar artery occlusion. Stroke 2008;39:2485-90

19. Zeumer H, Hacke W, Ringelstein EB. Local intraarterial thrombolysis in vertebrobasilar thromboembolic disease. AJNR Am J Neuroradiol 1983;4:401-04

20. Smith WS. Intra-arterial thrombolytic therapy for acute basilar occlusion: pro. Stroke 2007;38:701-03

21. Schulte-Altedorneburg G, Hamann GF, Mull M, et al. Outcome of acute vertebrobasilar occlusions treated with intra-arterial fibrinolysis in 180 patients. AJNR Am J Neuroradiol 2006;27:2042-47

22. Lindsberg PJ, Mattle HP. Therapy of basilar artery occlusion: a systematic analysis comparing intra-arterial and intravenous thrombolysis. Stroke 2006;37:922-28

23. Roth C, Papanagiotou P, Behnke S, et al. Stent-assisted mechanical recanalization for treatment of acute intracerebral artery occlusions. Stroke 2010;41:2559-67

24. Miteff F, Faulder KC, Goh AC, et al. Mechanical thrombectomy with a self-expanding retrievable intracranial stent (Solitaire $\mathrm{AB}$ ): experience in 26 patients with acute cerebral artery occlusion. AJNR Am J Neuroradiol 2011;32:1078-81

25. Costalat V, Machi P, Lobotesis K, et al. Rescue, combined, and standalone thrombectomy in the management of large vessel occlusion stroke using the Solitaire device: a prospective 50-patient singlecenter study: timing, safety, and efficacy. Stroke 2011;42:1929-35

26. Dorn F, Stehle S, Lockau H, et al. Endovascular treatment of acute intracerebral artery occlusions with the Solitaire stent: single-centre experience with 108 recanalization procedures. Cerebrovasc Dis 2012;34:70-77

27. Mordasini P, Brekenfeld C, Byrne JV, et al. Technical feasibility and application of mechanical thrombectomy with the Solitaire FR revascularization device in acute basilar artery occlusion. AJNR Am J Neuroradiol 2013;34:159-63

28. Espinosa de Rueda M, Parrilla G, Zamarro J, et al. Treatment of acute vertebrobasilar occlusion using thrombectomy with stent retrievers: initial experience with 18 patients. AJNR Am J Neuroradiol 2013;34:1044-48

29. Mourand I, Machi P, Milhaud D, et al. Mechanical thrombectomy with the Solitaire device in acute basilar artery occlusion. J Neurointerv Surg 2014;6:200-04

30. Dávalos A, Pereira VM, Chapot R, et al. Solitaire group: retrospective multicenter study of Solitaire FR for revascularization in the treatment of acute ischemic stroke. Stroke 2012;43:2699-705

31. Saver JL, Jahan R, Levy EI, et al. Solitaire flow restoration device versus the Merci retriever in patients with acute ischaemic stroke (SWIFT): a randomised, parallel-group, non-inferiority trial. Lancet 2012;380:1241-49

32. Strbian D, Sairanen T, Silvennoinen H, et al. Thrombolysis of basilar artery occlusion: impact of baseline ischemia and time. Ann Neurol 2013;73:688-94

33. Kellert L, Hametner C, Rohde S, et al. Endovascular stroke therapy: tirofiban is associated with risk of fatal intracerebral hemorrhage and poor outcome. Stroke 2013;44:1453-55 